\title{
Childhood Adversities and Traumata in Lebanon: A National Study
}

\author{
Lynn Itani ${ }^{1}$, Youmna C. Haddad ${ }^{1,2}$, John Fayyad ${ }^{1,2}$, Aimee Karam ${ }^{1,2}$ and Elie Karam ${ }^{1,2, *}$ \\ ${ }^{1}$ Institute for Development, Research, Advocacy \& Applied Care (IDRAAC), Beirut, Lebanon; ${ }^{2}$ Dept. of Psychiatry \& \\ Clinical Psychology, St. George Hospital University Medical Center, Balamand University, Faculty of Medicine, Beirut, \\ Lebanon
}

\begin{abstract}
Background: The goal of this paper is to map the total occurrence and evaluate the risk of co-occurrence of childhood adversities (CA) and a wide variety of childhood traumatic events (including war) in a national sample. Method: The nationally representative sample included 2,857 respondents and the instrument used was the Composite International Diagnostic Interview which screened for all CAs and traumatic events. Results: $27.9 \%$ experienced CAs; the most common were parental death and parental mental/substance use disorder. $70.6 \%$ experienced a war-related traumatic event during their lifetime, and around half of them (38.1\%) experienced it below the age of 18 years. $51.3 \%$ of the subjects experienced a traumatic event not related to war during their lifetime, and $19.2 \%$ experienced it before the age of 18 years. Sexual abuse, being a refugee during war, and experiencing a natural disaster were associated with female gender. Having any CA was associated with active war exposure (OR: 4.2, CI: 2.0-8.6); war-related direct personal trauma (OR: 3.9, CI: 1.5-10.0); war-related trauma to others (OR: 2.4, CI: 1.3-4.4); non-war direct personal trauma (OR: 3.8, CI: 2.07.4); and any non-war childhood traumatic event (OR: 1.9, CI: 1.1-3.1). Conclusion: Childhood is awash with adversities and traumatic events that co-occur and should be measured simultaneously; otherwise, the effects of a subset of traumata or adversities could be wrongly thought to be the contributor to negative outcomes under study.
\end{abstract}

Keywords: Adolescence, Childhood, Childhood adversities, Lebanon, Traumatic events, War trauma.

\section{INTRODUCTION}

Childhood is a formative stage whereby negative experiences may have a long term impact on many areas and levels of growth, including mental health. These negative experiences include childhood adversities, which can be grouped into neglect and abuse, parental loss and change in family structure, family economic adversity, parental psychopathology as well as severe physical illness during childhood [1]. Other stressful experiences, namely traumatic events, include the unexpected death to a loved one, bullying, car accidents, witnessing death/dead bodies/injury, witnessing atrocities, exposure to natural (earthquakes, flooding...) or manmade disasters (including wars: being a refugee, involved in combat...) and a host of others [2]. Exposure to adversities or traumatic events during childhood has been associated with having mental disorders in adulthood [1-8]. Hence, assessing the prevalence of such stressful events serves as an important guide for the planning of relevant interventions and policies.

Several national and cross-national studies have been published on the occurrence of childhood trauma and adversities [1, 2, 5, 9-12]. The reported cross-national rate of childhood adversities is $38.8 \%$, and that of lifetime traumatic events in European countries is $64 \%[1,2]$. No study on

\footnotetext{
*Address correspondence to this author at the IDRAAC (Institute for Development Research, Advocacy, \& Applied Care), Dept. of Psychiatry and Clinical Psychology, St. George Hospital University Medical Center, Faculty of Medicine, Balamand University, P.O. Box: 166227 Ashrafieh, Beirut, 1100 2110, Lebanon; Tel: + (961) 1 583583; Fax: + (961) 1 587190; Email: egkaram@idraac.org
}

adversities or traumatic events has been published on a national level (total population), to our knowledge, from the Arab world. The published community studies in the Arab countries, although focusing exclusively on specific subgroups (schools, high risk populations, confined communities) have shown that children and adolescents from the Arab world have been exposed to the panoply of traumatic events and childhood adversities described in other areas of the world such as sexual abuse, corporal punishment or violence from parents, physical fights or school violence, as well as neglect, psychological abuse etc [13-26].

Alas, the Arab world has been rife with wars flaring up in many Arab countries with dire consequences on the political stability of these countries, and of major impact on social cohesion and existential fears. Lebanon, a small democracy, which had been a haven of peace, started being the battlefield of many external and internal wars on and off since the 1970s. A variety of studies, including ones from our group, have documented exposure of Lebanese youth to war trauma [27-32], and a few to childhood adversities [33]. In addition, to our knowledge, the prevalence of traumatic events occurring during childhood outside the context of war has not been studied in Lebanon. Negative exposures (adversities and trauma) would gain from being evaluated in the same setting and the same individuals since they frequently co-occur in the same individual and their final effect on wellbeing may very well be due to the interactions of these negative exposures and not due to either alone. More importantly, this type of analysis is needed to set the stage for analyses linking co-occurring adversities and traumatic events with adult mental health outcomes. 
The current study aims to simultaneously assess the prevalence of: childhood adversities, war-related and nonwar related traumatic events (occurring at any age and during childhood) in a nationally representative sample from Lebanon. The different types of childhood adversities and traumatic events occurring during childhood are studied by gender and age cohort. Additionally, war-related and non-war related traumatic events are studied by age at first exposure. Last but not least, the study also investigates the association between childhood adversities and the types of traumatic events.

\section{MATERIALS AND METHODOLOGY}

\section{Sample}

Data was drawn from a nationally representative sample of Lebanese non-institutionalized adults $(\mathrm{N}=2,857)$ from the Lebanese Evaluation of the Burden of Ailments and Needs of the Nation (L.E.B.A.N.O.N.) study. The L.E.B.A.N.O.N. Study was conducted by the Institute for Development Research Advocacy and Applied Care (IDRAAC), in association with the Department of Psychiatry and Clinical Psychology at Balamand University Faculty of Medicine and St George Hospital University Medical Center, and is part of the World Health Organization (WHO)-World Mental Health Survey Initiative (WMH).This study was approved by the Institutional Review Board (IRB) committee of the Saint George University Medical Centre Faculty of Medicine, Balamand University, Lebanon, which is registered with the U.S Office of Human Research Protections (OHRP) in the Department of Health and Human Services. Additional details about the sampling procedure have been reported elsewhere [34, 35].

\section{Procedures}

Face-to-face interviews were conducted by lay interviewers using the Arabic version of the WHO Composite International Diagnostic Interview (CIDI) Version 3.0 [36]. All respondents $(n=2,857)$ completed Part I of the CIDI which is an assessment of core mental disorders. Respondents who met the lifetime criteria for any core disorder plus a probability sub-sample of other respondents $(n=1,031)$ were administered Part II of the CIDI which comprised other disorders and their correlates. Both Part I and Part II samples were weighted for differential probability of selection to achieve national representativeness. Details of the instrumentation and study procedures have been reported elsewhere $[34,35]$.

\section{Measures}

Information about childhood adversities and traumatic events was assessed in Part II of WMH-CIDI $3.0(n=1,031)$ through the Childhood section and the Post-Traumatic Stress Disorder (PTSD) section. Questions from these sections were developed using various scales more details could be found elsewhere [35].

\section{Childhood Adversities}

All the childhood adversities questions in the CIDI 3.0 (with the exception of sexual abuse) explicitly ask about stressors that occurred within the family during the respondent's childhood. Some variables were merged where it was judged meaningfully appropriate by the authors. Consequently, ten childhood adversities (occurring before age 18) were assessed, and were grouped into four categories (Table 1).

The first category is neglect and abuse and includes neglect from parents, physical abuse from parents or caregivers, and sexual abuse. More specifically, neglect is defined by being left alone unsupervised, being forced to do difficult chores, failing to receive proper clothing, food and medical attention, or reports of parents making little or no effort to ensure proper upbringing. Physical abuse from parents or caregivers (including step-parent(s) or adoptive parent(s)) includes the following caregiver behaviors: slapping, hitting, pushing, grabbing, shoving, throwing an object at or beating up the respondent. Sexual abuse is defined as having been raped, sexually assaulted or molested under the age of 18 for at least three times.

The second category is parental loss and includes parent death and change in family structure. Change in family structure includes parental divorce and other parental loss (adoption after the age of 2 , living with other relatives, being in foster care, or being in a detention center before age of 16).

The third category is parent psychopathology and includes parental mental or substance use disorder, family violence, and parental criminal behavior. Parent mental illness and substance use disorder is defined as either the father or mother having major depression, generalized anxiety disorder, panic disorder or substance use disorder during the respondent's childhood. Family violence means that the parents often hit, shoved, pushed, grabbed or slapped each other during the respondent's childhood, or that he/she witnessed physical fights at home before the age of 18. Parent criminal behavior is defined as the respondent reporting during childhood either father or mother having been involved in criminal activities, arrested or sent to prison.

The fourth category of childhood adversities is titled other types of adversities including family economic adversity and severe physical illness in childhood. Family economic adversity is defined as the absence of a male or female head of household (economic provider) while the other caregiver (if present) did not work at all or most of the time during childhood. Severe physical illness is defined as having a life-threatening illness or a chronic medical condition (cancer, epilepsy, or diabetes before the age of 18).

\section{Childhood Traumatic Events}

Traumatic events were assessed in the PTSD section of the CIDI. Some of these traumatic events exist in the context of war only, and including being: involved in combat either as a member of a military or an organized non-military group; being a volunteer or relief worker in war/terror region; being an unarmed civilian in a war zone where there was a revolution, military coup or an invasion; being a civilian in a terror region where terror was due to political, ethnic, religious, or other reasons; being a refugee or fleeing from home to a foreign country/place in order to escape danger or persecution. Some traumatic events were strictly not related to war, these are: being exposed to a natural disaster such as a devastating flood, an earthquake, or a hurricane, and being badly physically abused by spouse/partner. 
Table 1. Characteristics of childhood adversities in Lebanon.

\begin{tabular}{|c|c|c|c|c|c|c|c|c|}
\hline Childhood Adversity & \multicolumn{2}{|c|}{$\begin{array}{l}\text { Population } \\
\text { Prevalence }\end{array}$} & \multicolumn{2}{|c|}{ Gender } & \multicolumn{4}{|c|}{ Age Cohort } \\
\hline \multicolumn{9}{|l|}{ I. Neglect and abuse } \\
\hline Neglect & 32 & $1.6(.5)$ & $1.4(.7)$ & $1.7(.5)$ & $1.5(.5)$ & $1.8(.7)$ & $2.3(1.8)$ & $0.5(.3)$ \\
\hline Sexual abuse & 8 & $0.4(.1)$ & $0.2(.1)$ & $0.6(.3)^{* *}$ & $0.5(.3)$ & $0.5(.2)$ & $0.1(.1)$ & $0(0)+$ \\
\hline Any neglect and abuse & 98 & $5.4(1)$ & $5.1(1.2)$ & $5.7(1)$ & $5.7(1)$ & $7(1.8)$ & $3.0(1.9)$ & $3.2(1.7)$ \\
\hline \multicolumn{9}{|l|}{ II. Parental Loss } \\
\hline Parent death & 142 & $12.9(1.8)$ & $15.5(2.9)$ & $10.4(1.5)^{* *}$ & $8.5(1.7)$ & $14.4(3.3)$ & $12.7(3.8)$ & $29.7(5.1)^{* *}$ \\
\hline \multicolumn{9}{|l|}{ III. Parental Psychopathology } \\
\hline Mental/substance use disorder & 147 & $11.1(1.4)$ & $9.5(1.4)$ & $12.8(1.9)$ & $11.5(2)$ & $12.8(2.8)$ & $11.4(2.8)$ & $5.2(2.2)$ \\
\hline Family violence & 18 & $0.6(.2)$ & $0.3(.2)$ & $0.9(.4)$ & $0.8(.3)$ & $0.5(.2)$ & $0.1(.1)$ & $0.5(.5)$ \\
\hline Criminal behavior & 20 & $1.4(.4)$ & $1.3(.5)$ & $1.5(.6)$ & $1.3(.5)$ & $0.6(.2)$ & $2.7(2.1)$ & $1.5(1.2)$ \\
\hline Any parent psychopathology & 170 & $12.4(1.4)$ & $10.1(1.5)$ & $14.6(2.0)^{* *}$ & $12.7(1.9)$ & $13.7(2.8)$ & $12.5(2.9)$ & $7.3(2.6)$ \\
\hline \multicolumn{9}{|l|}{ IV. Other Adversity } \\
\hline Family economic adversity & 19 & $1.7(.6)$ & $1.2(.4)$ & $2.3(1.0)$ & $2.0(1.2)$ & $0.6(.4)$ & $0.9(.6)$ & $4.5(2.4)$ \\
\hline
\end{tabular}

$\beta$ : includes parent divorce and other parental loss

$* *=$ statistically significant $(\mathrm{p} \leq 0.05)$

$\$=$-value could not be computed due to having no cases in one or more categories

For the other types of traumatic events, the respondents were asked whether the event was related to the Lebanese wars or not. These events include: being kidnapped or held captive; being exposed to a life-threatening car accident; having any other life-threatening accident (including during work); being exposed to a man-made disaster such as a fire or an explosion; being subject to physical abuse from anyone else besides parents or spouse; being threatened at gunpoint/robbery; being stalked as in someone followed the respondents or kept track of their activities in a way that made them feel insecure; having an unexpected death to a loved one like murder, an accident, suicide, or a fatal heart attack at a young age; experiencing a traumatic event to a loved one such as kidnap, torture or rape; witnessing death, dead bodies or injury; accidentally causing death/injury to someone; intentionally causing serious injury, death or torture to someone; witnessing atrocities such as mass killing or mutilated bodies; experiencing any other traumatic event; and a private event that the respondent does not wish to disclose.

The traumatic events linked to war were classified into: active war exposure, general war exposure, direct personal trauma, and trauma to others (Table 2). The traumatic events not linked to war were classified into: direct personal trauma, trauma to others, and caused harm to someone (Table 3 ).

Respondents were asked about the age of onset of these events, and a "childhood traumatic event" (CTE) was defined as one that has occurred below the age of 18 years. It is to be noted that each event was assessed separately in the CIDI; therefore the same individual might endorse more than one traumatic event.

Although both CAs and CTEs represent exposure to stressors during childhood, they are presented here as separate items in the present report, since they show nonnegligible conceptual differences: by definition childhood adversities reflect intra-personal or interpersonal adversities related to the family, whereas CTE are more linked to nonfamilial events and some have a collective nature.

\section{Analysis Methods}

The SAS Software version 9.1 was used to generate weighted prevalences. Prevalence rates were stratified by gender and age cohorts for childhood adversities and traumatic events occurring under the age of 18 . Traumatic events 
Table 2. Characteristics of traumatic events linked to war (WAR TE) in Lebanon.

\begin{tabular}{|c|c|c|c|c|c|c|c|c|}
\hline & \multicolumn{2}{|c|}{ Population Prevalence } & \multicolumn{4}{|c|}{ Age of First Exposure of WAR TE } & \multicolumn{2}{|c|}{ WAR TE $<18$ y } \\
\hline & Lifetime WAR TE & WAR $T E<18 y$ & $<6$ & 6 to 11 & 12 to 17 & $18+$ & Males & Females \\
\hline & $\%(n)$ & $\%(n)$ & $\%($ se) & $\%($ se) & $\%($ se) & $\%($ se) & $\%($ se) & $\%($ se) \\
\hline \multicolumn{9}{|l|}{ I. Active war exposure } \\
\hline Involved in combat & $9.5(89)$ & $1.7(27)$ & $0(0)$ & $0.6(.6)$ & $18.1(1.7)$ & $81.3(1.7)^{* *}$ & $3.5(.5)$ & $0(.4) \ddagger$ \\
\hline Volunteer/rescue worker in war zone & $3.0(37)$ & $0.4(9)$ & $0(0)$ & $0(0)$ & $11.9(1.8)$ & $88.1(1.9)^{*}$ & $0.5(1.6)$ & $0.2(1.5)$ \\
\hline $\begin{array}{l}\text { Intentionally injured/tortured/killed } \\
\text { someone }\end{array}$ & $0.6(5)$ & $0.1(2)$ & $0(0)$ & $0(0)$ & $22.9(.9)$ & $77.1(1.2) \ddagger$ & $0.3(.3)$ & $0(.4) \ddagger$ \\
\hline Any active war exposure & $10.9(114)$ & $2.0(32)$ & $0(0)$ & $0.5(.7)$ & $17.5(1.2)$ & $82.0(1.3)^{* *}$ & $3.7(.7)$ & $0.2(.8)^{* *}$ \\
\hline \multicolumn{9}{|l|}{ II. General war exposure } \\
\hline Civilian in war zone & $55.2(620)$ & $29.0(292)$ & $11.5(1.2)$ & $21.1(1.1)$ & $21.8(1.0)$ & $45.5(1.1)^{* *}$ & $27(1.7)$ & $30.9(1.8)$ \\
\hline Civilian in terror region & $8.6(114)$ & $4.6(45)$ & $7.3(1.2)$ & $14.1(1.1)$ & $33.5(1.5)$ & $45.1(1.0)^{* *}$ & $5.0(1.6)$ & $4.3(1.7)$ \\
\hline Refugee & $37.7(447)$ & $17.2(173)$ & $9.2(.7)$ & $19.5(.9)$ & $19.3(1.8)$ & $51.9(.9)^{* *}$ & $12.7(.8)$ & $21.6(.9)^{* *}$ \\
\hline Any general war exposure & $64.7(725)$ & $35.4(351)$ & $13.3(.8)$ & $19.8(.9)$ & $21.6(.7)$ & $45.3(.8)^{* *}$ & $32.2(1.9)$ & $38.6(2.3)$ \\
\hline \multicolumn{9}{|l|}{ III. Direct personal trauma } \\
\hline Kidnapped & $3.1(47)$ & $0.7(10)$ & $0(0)$ & $2.8(1.4)$ & $19.3(2.0)$ & $77.9(.6)^{* *}$ & $1.4(.5)$ & $0.02(.4)^{* *}$ \\
\hline Threatened at gunpoint/robbery & $2.2(42)$ & $0.5(10)$ & $0(0)$ & $0(0)$ & $23.0(1.8)$ & $76.2(1.2)^{* *}$ & $0.6(1.5)$ & $0.3(1.4)$ \\
\hline Stalked & $2.3(29)$ & $0.3(6)$ & $0(0)$ & $3.3(.8)$ & $9.6(.7)$ & $87(.5)^{* *}$ & $0.4(.6)$ & $0.2(.7)$ \\
\hline Physical abuse from another person & $1.0(15)$ & $0.2(4)$ & $0(0)$ & $0(0)$ & $23.4(.7)$ & $76.6(1.8)^{* *}$ & $0.4(.4)$ & $0(.5) \div$ \\
\hline Accident $\dagger$ & $3.3(36)$ & $1.6(14)$ & $0(0)$ & $13.7(.7)$ & $36.1(.6)$ & $50.2(.5)^{* *}$ & $1.5(.5)$ & $1.7(.4)$ \\
\hline Any direct personal trauma & $7.7(107)$ & $2.7(31)$ & $0(0)$ & $7.9(.9)$ & $26.7(.7)$ & $65.4(1.1)^{* *}$ & $3.2(1.0)$ & $2.2(1.0)$ \\
\hline \multicolumn{9}{|l|}{ IV. Trauma to others } \\
\hline Traumatic event to a loved one & $7.6(92)$ & $2.7(30)$ & $1.2(1.4)$ & $10.4(1.2)$ & $24.8(1.3)$ & $63.6(1.5)^{* *}$ & $1.4(1.4)$ & $1.4(1.5)$ \\
\hline Witness death/dead body/severe injury & $18.0(208)$ & $5.7(69)$ & $0.3(1.2)$ & $8.7(1.3)$ & $25.5(1.4)$ & $65.6(1.3)^{* *}$ & $7.9(.5)$ & $3.6(.6)^{* *}$ \\
\hline Witnessed atrocities & $10.6(119)$ & $2.4(31)$ & $0.5(.9)$ & $4.2(.8)$ & $18.7(1.0)$ & $76.5(.9) * *$ & $3.3(1.6)$ & $1.5(2.0)$ \\
\hline Unexpected death to a loved one & $10.2(126)$ & $2.7(31)$ & $0(0)$ & $10.1(.8)$ & $17.7(.9)$ & $72.2(1.0)^{* *}$ & $2.9(1.5)$ & $2.6(1.4)$ \\
\hline Any trauma to others & $31.1(354)$ & $11.5(124)$ & $0.5(1.5)$ & $10.8(1.8)$ & $24.3(1.6)$ & $64.4(1.7)^{* *}$ & $12.9(1.7)$ & $10(1.8)$ \\
\hline Other event & $0.7(10)$ & $0.1(5)$ & $0(0)$ & $1(.7)$ & $7.1(.8)$ & $91.8(.9)^{* *}$ & $0.2(.5)$ & $0.08(.6)$ \\
\hline Any war traumatic event & $70.6(776)$ & $38.1(390)$ & $12.3(1.8)$ & $19.7(1.9)$ & $21.8(1.8)$ & $46.3(1.7)^{* *}$ & $36.5(1.9)$ & $39.7(1.8)$ \\
\hline
\end{tabular}

$\dagger$ : includes car accident and life-threatening accident

$* *$ : statistically significant: $\mathrm{p} \leq 0.05$

$\$$ : p-value could not be computed due to small numbers

were assessed in the general population, and prevalences were generated according to categories of age of onset for each event (age groups: below 6, 6 to 11, 12 to 17 and above 18 years). Chi-square test and Fischer exact test were used for comparisons across age of exposure groups, gender, and age cohort groups. Also, the number of childhood adversities and childhood traumatic events were evaluated. The association between the specific types of childhood adversities and the types of traumatic events was investigated using simple logistic regression. Odds rations were used as measures of association. 95\% confidence intervals (CI) were reported with statistical significance at the alpha level of 0.05 .

\section{RESULTS}

\section{Prevalence of Childhood Adversities by Gender}

More than a quarter of Lebanese adults (27.9\%) reported having any childhood adversity: $20.6 \%$ of the population experienced one childhood adversity, whereas $4.9 \%$ experienced two, and $2.6 \%$ experienced three or more. The most prevalent childhood adversity was parental death $(12.9 \%)$ followed by parental mental / substance use disorder (11.1\%). Other adversities were less common ranging between $0.4 \%$ for sexual abuse to $4.4 \%$ for physical abuse from parents/caregivers (Tables $\mathbf{1}$ and $\mathbf{4}$ ). 
Table 3. Characteristics of traumatic events not linked to war (NONWAR TE) in Lebanon.

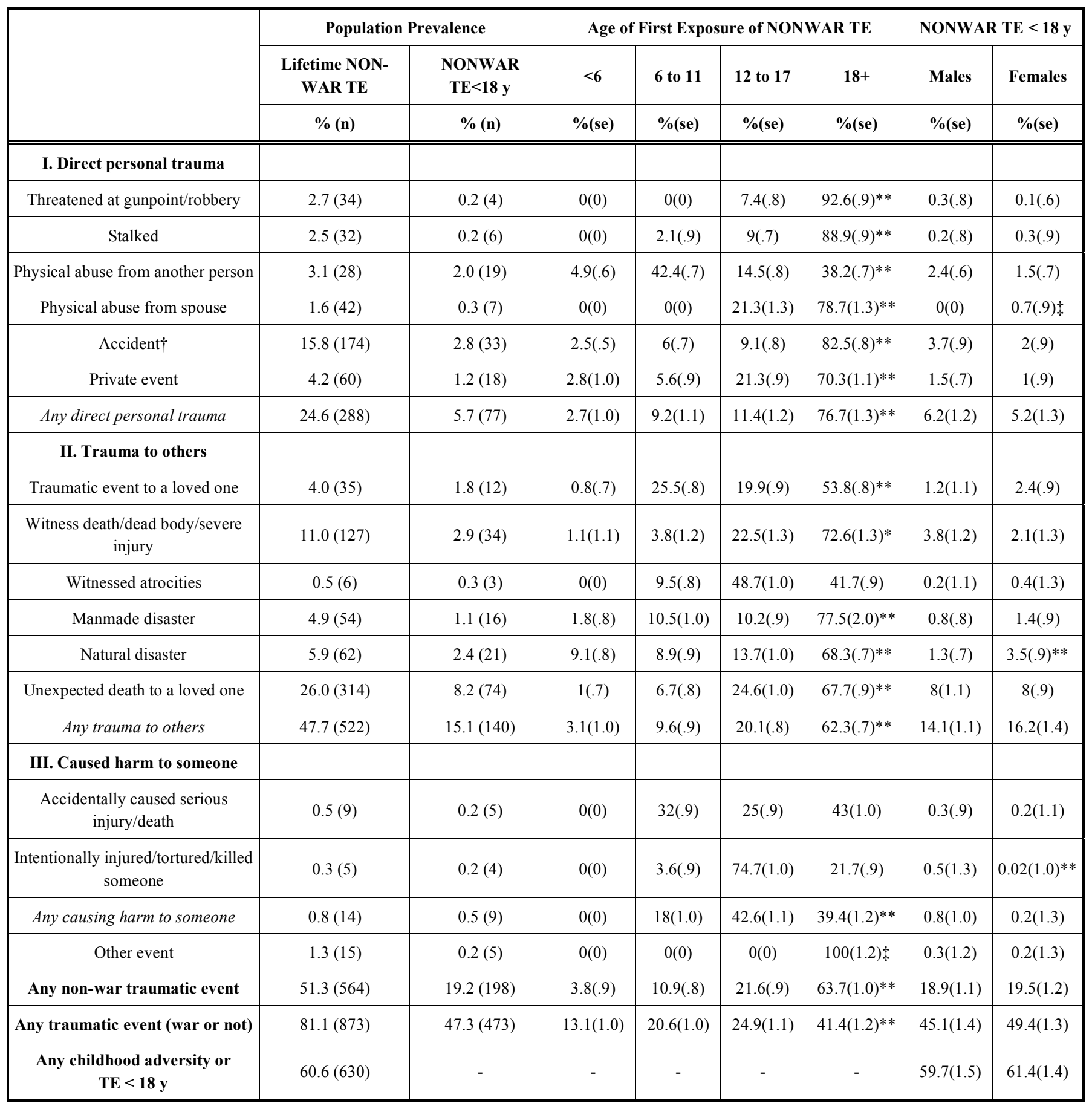

$\uparrow$ : includes car accident and life-threatening accident

**: statistically significant: $\mathrm{p} \leq 0.05$

\$: p-value could not be measured due to small numbers

In general, there was no significant difference in the total prevalence of any childhood adversity between genders ( $26.8 \%$ for females vs. $29.1 \%$ for males, $\mathrm{p}=0.5$ ). However, females reported more sexual abuse $(0.6 \%$ vs. $0.2 \%, \mathrm{p}=0.05)$ and males reported significantly more parental death $(15.5 \%$ vs. $10.4 \%, \mathrm{p}=0.04)$. Females had a tendency to report more parental mental /substance use diagnosis $(12.8 \%$ vs. $9.5 \%$, $\mathrm{p}=0.07$ ), and family violence ( $0.9 \%$ vs. $0.3 \%, \mathrm{p}=0.06)$ than males (Table 1).

\section{Prevalence of Childhood Adversities by Age Cohort}

There was no significant trend in reporting childhood adversities among age cohorts $(\mathrm{p}=0.2)$, although the oldest age cohort had the highest rate of adversities (35.1\%). A notable exception, parental death, decreased by about $70 \%$ from the $65+$ years age cohort $(29.7 \%)$ to the $18-34$ years age cohort $(8.5 \% ; \mathrm{p}<0.001)$ (Table 1). 


\section{Prevalence of Traumatic Events and Age of First Expo- sure}

More than $80 \%$ of Lebanese adults reported being exposed to any traumata in their lifetime; about half of individuals experiencing trauma $(47.3 \%)$ had the first traumatic event before the age of 18 years. $22.8 \%$ reported being exposed to one event during childhood, $12.9 \%$ to two, and $11.3 \%$ to three or more. $71 \%$ of respondents reported a lifetime traumatic event that was related to war, and $38.1 \%$ stated that a war-related event happened before the age of 18 . $18.5 \%$ were exposed to one war-related event during childhood, $11.9 \%$ to two, and $7.7 \%$ to three or more events. Moreover, $51.3 \%$ of the adults reported a lifetime event that was not related to war with $19.2 \%$ stating that it happened before age $18.15 .4 \%$ of respondents reported being exposed to one traumatic event not linked to war during childhood, while $3 \%$ were exposed to 2 events, and $0.9 \%$ to three or more (Tables 2, 3, and 4).

The most common traumatic events related to war (occurring at any age) were the same ones that occurred most commonly before the age of 18 in the total population at any age: civilian in war zone $(55.2 \%)$, being a refugee $(37.7 \%)$, witnessing death/dead bodies/severe injury (18.0\%), witnessing atrocities $(10.6 \%)$, and the unexpected death to a loved one $(10.2 \%)$. Again, for traumatic events not linked to war, the most commonly reported events occurring during childhood were the ones that occurred at any age, including: unexpected death to a loved one $(26.0 \%)$, accidents $(15.8 \%)$, and witnessing death/dead body/injury (11.0\%) (Tables 2 and 3).

Most of the war-related events occurred for the first time in adulthood except for: civilian in war zone/terror region, refugee and having an accident. $46.3 \%$ of war-related events occurred for the first time above $18,21.8 \%$ occurring in the age group $12-17$, and $19.7 \%$ in the age group 6-11 and $12.3 \%$ below the age of 6 years. As for traumatic events not related to war, $3.8 \%$ of them occurred for the first time in the age group below 6 , while $10.9 \%$ in the $6-11,21.6 \%$ between 12 and 17 , and $63.7 \%$ above the age of 18 . Like the events related to war, most of the events not related to war occurred in adulthood except for: being physically abused from a person other than parents/romantic partner, accidentally causing serious injury/death, intentionally injuring/torturing/killing someone, and witnessing atrocities (Tables $\mathbf{2}$ and $\mathbf{3}$ ).

\section{Prevalence of Childhood Traumatic Events by Gender}

There was no significant difference for the occurrence of the general category "any event related to war" by gender. Combining being involved in combat with being a volunteer/rescue worker showed that the prevalence of being active in a war zone as such was higher in males than females $(3.7 \%$ vs. $0.2 \% \mathrm{p}<0.001)$. Also, males were more likely to be kidnapped ( $1.4 \%$ vs. $0.02 \%, \mathrm{p}<0.001)$, and to have witnessed death/dead bodies/severe injury ( $7.9 \%$ vs. $3.6 \%, \mathrm{p}=0.01)$. Females were more likely to be refugees $(21.6 \%$ vs. $12.7 \%$, $\mathrm{p}=0.01)$ (Tables 2 and $\mathbf{3}$ ).

For events not related to war, there was no major significant difference between genders (possibly due to small numbers). Males were more likely to report intentionally injur- ing/torturing/killing someone $(0.5 \%$ vs. $0.02 \%, \mathrm{p}<0.001)$. Females were more likely to report natural disasters $(3.5 \%$ vs $1.3 \%, \mathrm{p}<0.001$ ) (Tables $\mathbf{2}$ and $\mathbf{3}$ ).

\section{Prevalence of Childhood Traumatic Events by Age Co- hort}

The prevalence of "any childhood traumatic event linked to war" in the different age cohorts was as follows: $52.2 \%$ for $18-34 ; 46.0 \%$ for $35-49 ; 5.2 \%$ for $50-64$ and $5.3 \%$ for $65+$. As for the traumatic events not linked to war, the prevalence of "any childhood traumatic event not linked to war" in the different age cohorts was: $26.7 \%$ for $18-34 ; 14.1 \%$ for $35-49 ; 12.9 \%$ for $50-64$; and $6.5 \%$ for $65+$. In fact, this trend of the younger age cohorts (18-34 and 35-49) being more exposed to traumatic events during childhood was consistent across all the types of traumatic events, whether they were linked to war or not (data available upon request).

\section{Prevalence of Childhood Adversities and Childhood Traumatic Events}

$60.6 \%$ of the Lebanese population experienced at least one adversity or traumatic event before age 18 . There were no significant differences in exposure to such stressors between males and females. Younger age cohorts reported significantly more exposure to any of these stressors than older cohorts $(\mathrm{p}<0.001)$ (Table 3$)$.

\section{The Association between Types of Childhood Adversities and Types of Traumatic Events}

Out of respondents who experienced a CA, 43.4\% reported a war-related childhood traumatic event, whereas $27.2 \%$ reported a non-war childhood traumatic event. As for respondents who reported a war-related childhood traumatic event, $31.7 \%$ reported a childhood adversity, whereas $26.5 \%$ reported a childhood traumatic event not linked to war. Out of respondents who reported a childhood traumatic event not linked to war, 39.5\% reported a childhood adversity whereas $52.6 \%$ reported a war-related childhood traumatic event. (more details about the co-occurrence of CAs and TEs are presented in Fig. 1).

Out of the childhood adversities studied, "neglect and abuse" was associated with the greatest number of types of traumatic events. Other childhood adversities were also clearly related with the different types of traumatic events, with significant odds ratios, except for "parental death". (Appendix A).

\section{DISCUSSION}

Lebanon has witnessed repeated occurrence of wars starting in the mid-seventies of the last century with one long stretch (1975 to 1990) and occasional shorter episodes since then, lasting a month or less which we have shown in previous publications to have impacted the Lebanese both physically and mentally [34, 35]. Many countries around the world, and more so recently in the Arab world, have had these unfortunate experiences. The burden of these war traumata evidently becomes heavier when considered against the background of other traumatic events and the wellrecognized adversities that occur in childhood. The purpose 
Table 4. Exposure to CAs and TEs $<18$ years in the Lebanese population.

\begin{tabular}{|c|c|c|c|c|c|c|c|c|c|c|}
\hline & \multicolumn{2}{|c|}{ CA } & \multicolumn{2}{c|}{ War TE $<18$ y } & \multicolumn{2}{c|}{ Non-war TE $<18$ y } & \multicolumn{3}{c|}{ Any TE $<18$ y } & \multicolumn{2}{c|}{ Any TE $<18$ y or CA } \\
\hline Number & $\mathbf{n}$ & $\mathbf{\%}(\mathbf{s e})$ & $\mathbf{n}$ & $\mathbf{\%}(\mathbf{s e})$ & $\mathbf{n}$ & $\mathbf{\%}(\mathbf{s e})$ & $\mathbf{n}$ & $\mathbf{\%}(\mathbf{s e})$ & $\mathbf{n}$ & \% (se) \\
\hline \hline None & 686 & $72.2(2.1)$ & 641 & $61.9(2.7)$ & 833 & $80.8(1.9)$ & 558 & $52.7(2.5)$ & 406 & $39.2(1.4)$ \\
\hline One & 237 & $20.5(2.3)$ & 185 & $18.5(1.6)$ & 150 & $15.4(1.9)$ & 210 & $22.8(2.0)$ & 252 & $24.3(1.2)$ \\
\hline Two & 72 & $4.8(1.0)$ & 114 & $11.9(2.0)$ & 36 & $3.0(1.0)$ & 127 & $12.9(2.1)$ & 166 & $16(1.1)$ \\
\hline Three & 23 & $1.6(0.4)$ & 53 & $5.3(1.0)$ & 9 & $0.4(0.2)$ & 61 & $5.6(1.3)$ & 90 & $8.7(0.9)$ \\
\hline Four & 9 & $0.8(0.4)$ & 24 & $1.3(0.3)$ & 1 & $0.07(0.06)$ & 40 & $3.1(0.6)$ & 42 & $4.1(1.1)$ \\
\hline Five or more & 4 & $0.2(0.1)$ & 14 & $1.1(0.2)$ & 2 & $0.4(0.05)$ & 35 & $2.6(0.7)$ & 80 & $7.7(1.2)$ \\
\hline
\end{tabular}

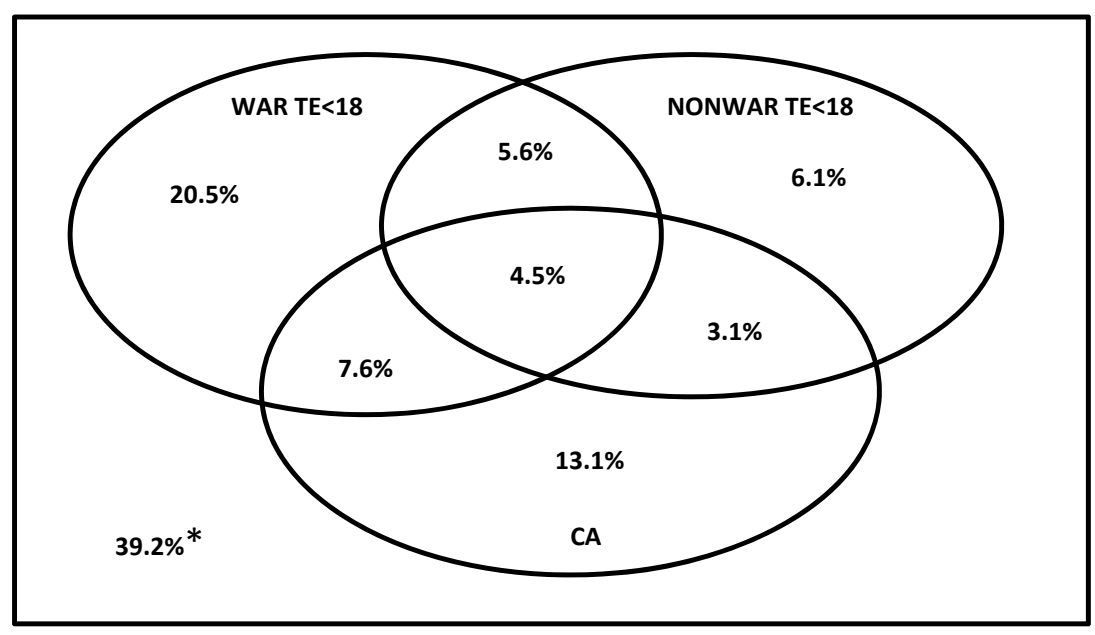

Fig. (1). The co-occurrence of CAs, war CTEs, and non-war CTEs in the total sample.

*: This group does not have any childhood adversities or childhood traumatic events.

of this paper is to provide, to our knowledge, the first nationally representative rates of war and non-war traumatic events, as well as rates of childhood adversities. Since all of these negative situations rarely occur in isolation or in a vacuum, we reported the association of childhood adversities with war and non-war traumatic events. Exposure to trauma might not be a totally passive experience across the range of traumata, both at individual and group levels, and thus the final effect on childhood and adulthood mental health would be the result of the interaction of all these negative experiences. As an example, exposure to war events during adolescence may not be totally independent from parental death or abuse/neglect experiences in the same adolescent: on the contrary it may be very likely that psychological processes link all these stressors together whereby teenage risk-taking (leading to war exposure) may be a reaction to feelings of loss, anger or rebellion following parental death, abuse or neglect.

The results of this study showed that more than a quarter of the Lebanese adults experienced a childhood adversity and almost half $(47.3 \%)$ of them experienced a traumatic event before age 18 years. One explanation for traumatic events being more prevalent than childhood adversities could be that the latter constitutes situations that are interpersonal, and thus within a subgroup of families, whereas traumatic events, especially those linked to war, are much more likely to affect wider segments of the population.

The prevalence of childhood adversities in Lebanon $(27.9 \%)$ is lower than the cross-national rate $(38.8 \%)$ found in the WHO-WMH Survey Initiative conducted in 21 countries (including Lebanon) using similar methodology [1]. As in the WMH surveys, parental death is the most commonly reported childhood adversity: with younger cohorts in Lebanon reporting losing a parent in early life less often than older cohorts, reflecting probably the continuous improvement in life expectancy. The rate of physical abuse in Lebanon is about half of what is reported internationally and is more reported, although without statistical significance, in younger cohorts. There might be an underreporting of physical abuse and violence across generations possibly because of the cultural perception, and more so in the older Lebanese generations, of corporal punishment as an acceptable and proper parenting strategy $[13,19,20,25,37,38]$. Moreover, less than $0.5 \%$ of our sample reported sexual abuse that is four times lower than the cross-national rate $(1.6 \%)$, but similar to the rate in high-middle income countries $(0.6 \%)$ [1]. This finding, could be argued not to be a true representation of reality since the victims might be suffering in silence in a culture where reporting on such matters is not encouraged. The rate of sexual abuse reported by a non-national 
study on children in Lebanon was higher, although possibly due to a different definition of sexual abuse [33].

More than $80 \%$ of respondents reported being exposed to any traumatic event, with almost half of them occurring before age 18 . We assessed systematically and for each of the traumatic events (any) whether they were linked to war or not. We did so because of the specifics of Lebanon's history. $87.1 \%$ of traumatic events occurring at any time were related to war and this was $80.5 \%$ for all traumatic events occurring before the age of 18 years. Additionally, the most prevalent traumatic events in Lebanon were war-related: refugee and civilian in a war zone. In the WMH cross-national data, the most commonly reported traumata across the life span were the death of a loved one and witnessing violence [39]: this is similar to our results in Lebanon if we only consider traumatic events that are not linked to war.

We found an interesting and uneven distribution of exposure to war events. The war related traumatic events that involved a lower degree of passivity (eg. combat, volunteer worker, witnessing death/injury and witnessing atrocities) as well as the events that have to do with direct, personal and intentional maltreatment during the war (kidnapping, physical abuse from another person, threatened at robbery, and stalking) occurred more commonly in adulthood. By contrast, the war related events which were much more general or practically independent of the victim occurred evenly in childhood /adolescence and adulthood.

Additionally, traumatic events linked to war that were related to a lower degree of passivity in war zones were more likely to occur in males than females at all ages (and also before 18). The same tended to be true for being stalked and witnessing atrocities although this did not reach statistical significance possibly because of small numbers. Such gender differences were due to males' higher involvement in war [17, 40-42]. Females, on the other hand, were more likely to be refugees during childhood: this could be due to the fact that younger females would tend to flee their hometowns more and young males may have stayed behind to fight or work.

For traumatic events not related to war, females had a greater rate of having physical abuse from the spouse/partner at all ages and even below age 18. The latter finding could be attributed to earlier marriage among some females. The prevalence of early marriage (below age 18) in Lebanon was $19.4 \%$ (data from the L.E.B.A.N.O.N. study). It is important to note that uncontrollable events such as the unexpected death to a loved one and traumatic event to a loved one were not related to gender (whether related to war or not).

In general, respondents belonging to younger age cohorts (18-34, 35-49) reported greater exposure below age 18 to trauma than respondents belonging to older age cohorts (50-64 and 65+), whether the trauma was war-related or not. For war-related events, this is attributed to the fact that the older age cohorts would have been in their 20's, and thus no more adolescents or children (the focus of this study) at the onset of the first episode of wars in Lebanon in 1975. For events not liked to war, we cannot rule out that this is due to recall bias.

Finally, the associations between the traumatic event types and the childhood adversities highlight the need to study both of them at the same time. Both trauma and childhood adversities are related to mental health (and other) outcomes and they appear to be related to each other as well (via ways that we cannot explain with our data). Hence, it is important to account for both childhood adversities and traumatic events in models studying mental health outcomes, instead of investigating each type of stressor independently. A forthcoming paper from our group will report on adult mental health outcomes of combined childhood adversities and childhood traumatic events.

The results of this study should be interpreted in light of some limitations. First, data was collected through face to face interviews which may have led to a social desirability bias resulting in an underreporting of adversities and traumata, especially with regards to sensitive issues such as sexual and physical abuse. In the Lebanese culture, subjects might have more difficulty than their counterparts in western cultures believing in the confidentiality and anonymity of research projects, although this has not been proven to our knowledge. This concern led the originators of the CIDI to include the category "private events" without requesting from the subjects to disclose any additional data. In addition, there were some traumatic events that were not assessed in the CIDI such as: destruction of home, witnessing violence on TV, exposure to tear gas, witnessing firing on their home by tanks and heavy artillery, raids of the household, etc. Another limitation is related to the panoply of parental mental illnesses assessed: these include only mood, anxiety, and substance disorders without questions about bipolar disorders and psychotic spectrum disorders.

\section{CONCLUSION}

Childhood/adolescence are developmentally sensitive periods during which exposure to childhood adversities and traumatic events increases the risk of mental disorders in adulthood. This paper reports the first nationally representative study on the prevalence of these stressors in childhood/adolescence not only in Lebanon but also in the Arab world. Results show that around a third of the population has experienced a childhood adversity, and around half have experienced a traumatic event before the age of 18. Exposure to war TEs was reported by $70.6 \%$ of the sample, and by $38.1 \%$ of the sample before the age of 18 . This significant exposure to war trauma highlights the need for policies and interventions that address this issue in Lebanon as well as countries where military conflicts have occurred. The impact of these stressors and their respective contribution to the risk of adverse mental health outcomes is the focus of a forthcoming paper. We have demonstrated that both types of stressors (adversities and traumata) are highly prevalent during childhood and adolescence, and moreover, are statistically associated with each other. Therefore, future studies must take into account both types of stressors when investigating future mental health or other outcomes.

\section{CONFLICT OF INTEREST}

The authors confirm that this article content has no conflict of interest. 
Appendix A: Association of childhood adversities (Neglect and Abuse, Parent Divorce, Parent Death, Parent Psychopathology, Other Adversity and Any CA) with traumatic event types occurring below the age of 18 .

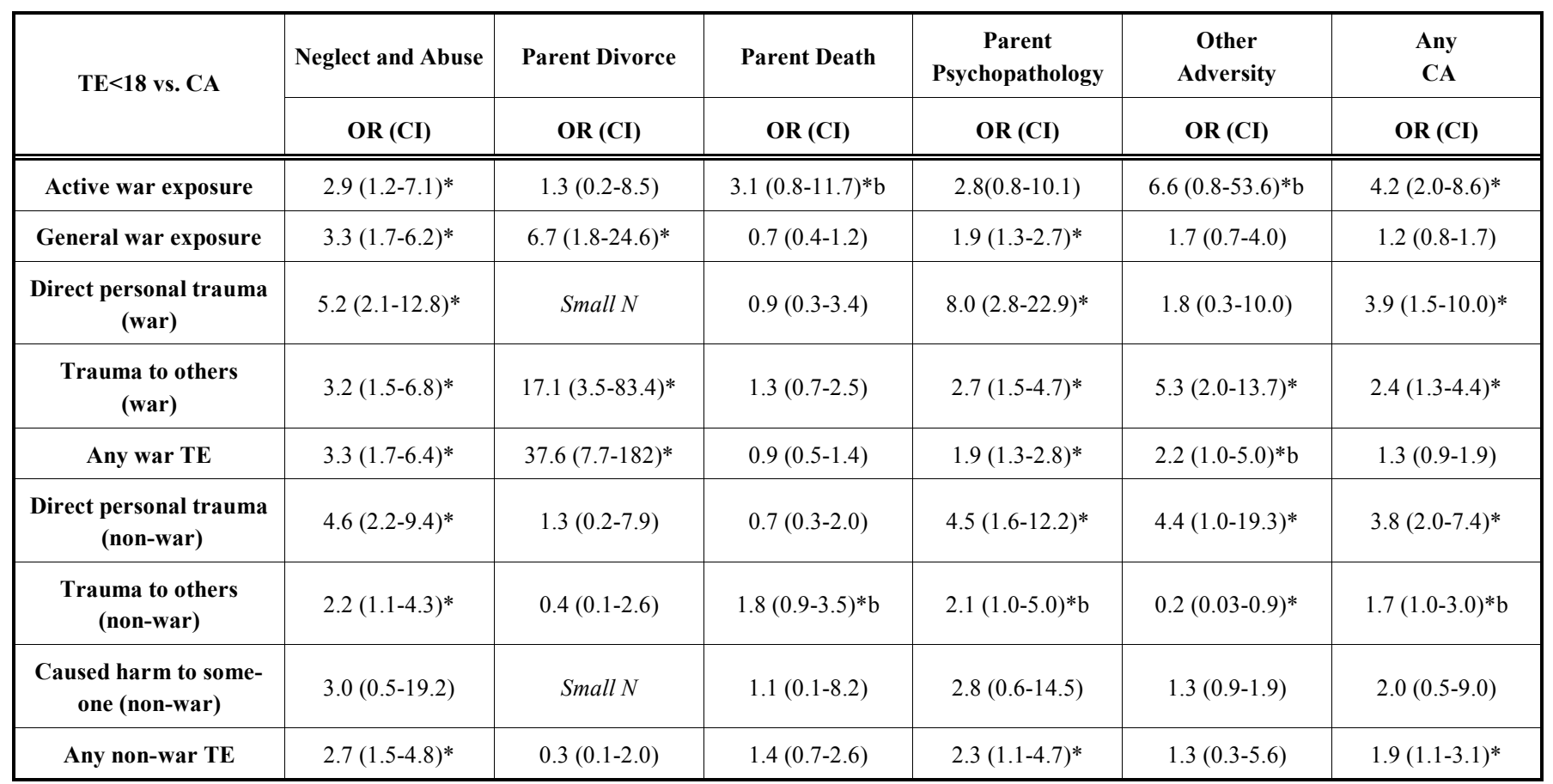

$*: \mathrm{p}<0.05 ; *$ b: $0.05 \leq \mathrm{p} \leq 0.09$

\section{ACKNOWLEDGEMENTS}

The Lebanese National Mental Health Survey (L.E.B.A.N.O.N.) is supported by the Lebanese Ministry of Public Health, the WHO (Lebanon), National Institute of Health / Fogarty International Center (R03 TW006481-01), Sheikh Hamdan Bin Rashid Al Maktoum Award for Medical Sciences, anonymous private donations to IDRAAC, Lebanon, and grants from AstraZeneca, Eli Lilly, Lundbeck, Novartis, Roche and Servier.

\section{REFERENCES}

[1] Kessler R, McLaughlin K, Green J, et al. Childhood adversities and adult psychopathology in the WHO World Mental Health Surveys. Brit J Psych 2010; 197: 378-85.

[2] Darves-Bornoz J, Alonso J, De Girolamo G, et al. Main traumatic events in Europe: PTSD in the European study of the epidemiology of mental disorders survey. J Trauma Stress 2008; 21(5): 455-62.

[3] Anda R, Whitfield C, Felitti V, et al. Adverse childhood experiences, alcoholic parents, and later risk of alcoholism and depression. Psychiatr Ser 2002; 53(8): 1001-9.

[4] Anda R, Brown D, Felitti V, et al. Adverse childhood experiences and prescribed psychotropic medications in adults. Am J Prev Med 2007; 32(5): 389-94.

[5] Benjet C, Borges G, Medina-Mora, M. Chronic childhood adversity and onset of psychopathology during three life stages: Childhood, adolescence and adulthood. J Psychiatr Res 2010; 44: 732-40.

[6] Chapman D, Anda R, Felitti V, et al. Adverse childhood experiences and the risk of depressive disorders in adulthood. J Aff Dis 2004; 82: 217-25.

[7] Edwards V, Holden G, Anda R, et al. Experiencing multiple forms of childhood maltreatment and adult mental health: results from the Adverse Childhood Experiences (ACE) Study. Amer J Psychiatr 2003; 160(8): 1453-60.

[8] Tiecher M, Jaqueline J. Childhood Maltreatment and psychopathology: a case for ecophenotypic variables as clinically and neurobiologically distinct subtypes. Amer J Psychiatr 2013; 10(170): 1114-33.
[9] Bruffaerts R, Demyttenaere K, Borges G, et al. Childhood adversities as risk factors for onset and persistence of suicidal behavior. Brit J Psychiatr 2010; 197(1): 20-7.

[10] Fujiwara T, Kawakami N. Association of childhood adversities with the first onset of mental disorders in Japan: Results from the World Mental Health Japan, 2002-2004. J Psychiatr Res 2011; 45(4): 481-7.

[11] McLaughlin K, Green J, Gruber M, et al. Childhood adversities and adult psychopathology in the National Comorbidity Survey Replication (NCSR) II: Associations with persistence of DSM-IV disorders. Arch Gen Psychiatr 2010; 67(2): 124-32.

[12] Williams S, Williams D, Stein D, et al. Multiple traumatic events and psychological distress: the South Africa stress and health study. J Trauma Stres 2007; 20(5): 845-55.

[13] Abolfotouh M, El-Bourgy M, Seif El Din A, et al. Corporal punishment: Mother's disciplinary behavior and child's psychological profile in Alexandria, Egypt. J Forensic Nurs 2009; 5(1): 5-17.

[14] Al-Mahroos F. Corporal punishment and psychological maltreatment among school girls in Bahrain. Bahrain Med Bulletin 1997; 19(3): 70-3.

[15] Al-Mahroos F, Abdulla F, Kamal S, et al. Child abuse: Bahrain's experience. Child Abuse Negl 2005; 29: 187-93.

[16] Dyregrov A, Gjestad R, Raundalen M. Children exposed to warfare: a longitudinal study. J Trauma Stress 2002; 15(1): 59-68.

[17] Giacaman R, Shannon H, Saab H, et al. Individual and collective exposure to political violence: Palestinian adolescents coping with conflict. Eur J Public Health 2007; 17(4): 361-8.

[18] Hadi F, Llabre M. The Gulf crisis experience of Kuwaiti children: psychological and cognitive factors. J Trauma Stress 1998; 11(1): 45-56.

[19] Ibrahim N, Jalali E, Al-Ahmadi J, et al. Prevalence, risk factors and outcome of childhood abuse reported by female university students in Jeddah. J Egypt Public Health Asstn 2008; 83(5): 329-51.

[20] Jumaian A. Prevalence and long-term impact of sexual abuse among a sample of male college students in Jordan. Eastern Med Health J 2001; 7(3): 435-40.

[21] Lansford J, Alampay L, Al-Hassan S, et al. Corporal punishment of children in nine countries as a function of child gender and parent gender. Int J Pediatr 2010; 2010: 672780. 
[22] Morgos D, Worden J, Gupta L. Psychosocial effects of war experiences among displaced children in Southern Darfur. Omega 2008; 56(3): 229-53.

[23] Qouta S, Punamäki R, El Sarraj E. Prevalence and determinants of PTSD among Palestinian children exposed to military voiolence. Eur Child Adolesc Psychiatr 2003; 12(6): 265-72.

[24] Qouta S, Punamäki R, El Sarraj E. Mother-child expression of psychological distress in war trauma. Clin Child Psych Psychiatr 2005; 10(2): 135-56.

[25] Youssef R, Attia M, Kamel M. Children experiencing violence I: Parental use of corporal punishment. Child Abuse Negl 1998; 22(10): 959-73.

[26] Youssef R, Attia M, Kamel M. Children experiencing violence II: Prevalence and determinants of corporal punishment in schools. Child Abuse Negl 1998; 22(10): 975-85.

[27] Chimienti G, Nasr J, Khalifeh I. Children's reactions to war-related stress: Affective symptoms and behavior problems. Social Psychiatr Psychiatr Epidem 1989; 24(6): 282-7.

[28] Cordahi C, Karam E, Nehme G, et al. Les Orphelins De La Guerre Experience Libanaise et Méthodologie D'un Suivi Prospectif. Stress et Trauma 2002; 2(4): 227-35.

[29] Karam E, Fayyad, J, Salamoun M, et al. Assessment study of psychosocial status of children and adolescents in the south of lebanon and southern suburbs of beirut after the july 06 war (SSSS) 2007. Beirut: HCC/HI/EU-ECHO/IDRAAC.

[30] Karam E, Mneimneh Z, Fayyad J, et al. Lifetime prevalence of mental disorders in Lebanon: First onset, treatment and exposure to war. PLOS Med 2008; 5(4): e61.

[31] Karam E, Noujeim J, Saliba S, et al. PTSD: How Frequently Should the Symptoms Occur? The Effect on Epidemiologic Research. J Traumat Stress; 9(4): 899-905.

[32] Saigh P. The development of posttraumatic stress disorder following four different types of traumatization. Behaviour Res Therap 1991; 29(3): 213-6.
[33] Usta J, Farver J. Child sexual abuse in Lebanon during war and peace. Child: Care, Health Develop 2010; 36(3): 361-8.

[34] Karam E, Mneimneh Z, Karam A, et al. Prevalence and treatment of mental disorders in Lebanon: A national epidemiological survey. Lancet 2006; 367(9515): 1000-6.

[35] Karam E, Fayyad J, Karam A, et al. Effectiveness and specificity of a classroom-based group intervention in children and adolescents exposed to war in Lebanon. World Psychiatry 2008a; 7(2):103-9.

[36] Kessler R, Ustun T. The World Mental Health (WMH) survey initiative version of the WHO-CIDI. Int J Methods Psychiatr Res 2004; 13: 95-121.

[37] Fayyad J, Farah L, Cassir Y, et al. Dissemination of an evidencebased intervention to parents of children with behavioral problems in a developing country. Eur Child Adolesc Psychiatr 2010; 19(8): 629-36.

[38] Al-Fayez G, Ohaeri J, Gado O. Prevalence of physical, psychological, and sexual abuse among a nationwide sample of Arab high school students: association with family characteristics, anxiety, depression, self-esteem, and quality of life. Soc Psychiatry Psychiatr Epidemiol; 47(1): 53-66.

[39] Stein D, Chiu W, Hwang I, et al. Cross-national analysis of the associations between traumatic events and suicidal behavior: Findings from the WHO World Mental Health Surveys. PLOS ONE 2010; 5(5): e10547.

[40] Macksoud M, Aber J. The war experiences and psychosocial development of children in Lebanon. Child Develop 1996; 67(1): 70-88.

[41] Qouta S, El Sarraj E, Punamäki R. Mental flexibility as resiliency factor among children exposed to political violence. Int $\mathrm{J}$ Psych $2001 ; 36(1): 1-7$

[42] Thabet A, Abed Y, Vostanis P. Comorbidity of PTSD and depression among refugee children during war conflict. J Child Psych Psychiatr 2004; 45(3): 533-42.

Received: June 03, 2014
(C) Itani et al.; Licensee Bentham Open.

Revised: August 02, 2014

Accepted: August 02, 2014

This is an open access article licensed under the terms of the Creative Commons Attribution Non-Commercial License (http://creativecommons.org/licenses/by-nc/3.0/) which permits unrestricted, non-commercial use, distribution and reproduction in any medium, provided the work is properly cited. 